\title{
Introduction to special issue of JCTR on functional coatings
}

\author{
Mark Nichols
}

(C) American Coatings Association 2020

This special issue of the Journal of Coatings Technology and Research is devoted to functional coatings that provide more than the traditional coating roles of substrate protection and aesthetic enhancement. This is a rapidly growing area of coatings research and covers many different types of coatings. Perhaps the most widely researched area concerns superhydrophobic coatings, which are coatings that display very high water contact angles. Coatings that display this behavior are being actively developed to prevent ice accumulation (ice-phobic), provide self-cleaning, repel insects, and separate oil and water for pollution mitigation, along with many other applications. Superhydrophilic coatings are also being developed and are characterized by very low water contact angles, which endow coatings with antifogging characteristics. Other functional coatings include intumescent coatings to decrease the spread of fires, coatings to allow the slow release of fertilizer and improve crop production, and smart coatings that repair themselves or actively resist corrosion when they are damaged. The commercialization of these coatings is just beginning but promises to rapidly increase as researchers solve the challenging technical issues of cost, durability, and appearance.

We believe that, by devoting a special issue focused on this topic, the readers of JCTR will develop a deeper appreciation for this growing area of coatings technology and that these papers will provide a valuable contribution to the literature in this area.

Publisher's Note Springer Nature remains neutral with regard to jurisdictional claims in published maps and institutional affiliations.

M. Nichols $(\bowtie)$

Dearborn, MI, USA

e-mail: jctreditor@mlnichols.org 